\title{
Adolescent spirituality with the support of adults
}

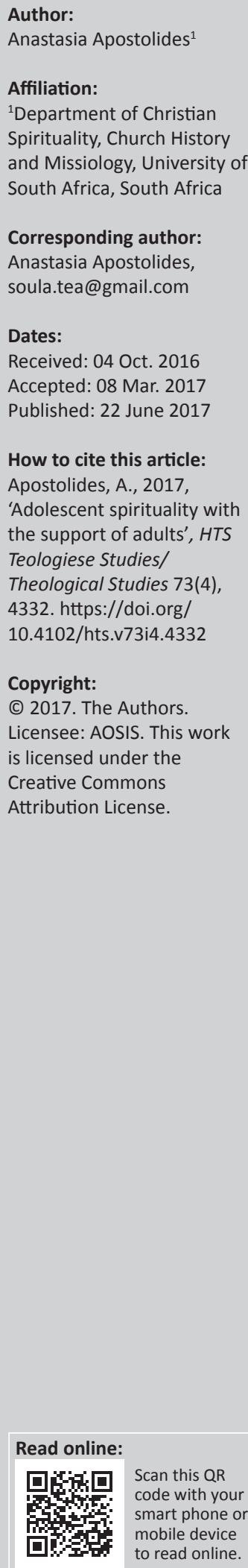

\begin{abstract}
Adolescence can be a trying time for adolescents and those with whom they share their journey, directly or indirectly. In a fast-paced world where adolescents want to conform to their youth or popular culture, the adolescent may become inundated and confused with all that is continuously taking place in their social context. This article argues that with the support of adults, adolescents may be guided to explore, experience and live out their spiritual identities through their popular or youth culture in a healthy way.
\end{abstract}

\section{Introduction}

In this article, it will be argued that when allowed to live out and express their own form of spiritualty with the support of the adults who care for them (parents, grandparents, teachers, ministers and so on), adolescents grow into happy and well-balanced adults. However, if they are prevented from exploring their spiritual identities in the correct way, or are not adequately supported by the adults around them, adolescents can fall into inauthentic spiritualties (a term used by Perrin [2007:24]) that may lead them to get involved in activities that may have a negative impact in their lives. The term inauthentic spiritualties will be explained below.

Adolescents use youth or popular culture to understand themselves, their place within this culture and other adolescents within their social environments (people of all ages use aspects of their social context to form identity and spirituality). The use of youth or popular culture has an impact on the adolescent's identity and spiritual development. However, some aspects of popular or youth culture may not be of value to the adolescent's identity or spiritual life. Often, the values adolescents acquire at this stage of their lives are carried through to adulthood.

\section{Adolescents and their spiritual lives}

Adolescence is a trying time in a human being's life, as there are sudden changes in his or her physical and emotional self (Fowler 1981:151). The adolescent becomes awkward within his or her social setup, suddenly self-aware of who he or she is (Coles 1998:135). At this stage of life, adolescents may find themselves confused and anxious as to whether they are fitting in with their social peers, often rejecting their parents' values (Coles 1998:143). In their search for independence, and during their sexual maturity and moral dilemmas, the adolescent often feels isolated and misunderstood (Coles 1998:134). Doka (2011) ${ }^{1}$ explains how 'throughout adolescence, the adolescent struggles with three core issues: independence, intimacy and identity'.

\section{The adolescent and identity}

Identity is an essential part of spirituality. People form identity and spirituality by integrating aspects of their social environment into their identity and spirituality. Sax (2010:181) explains how the core of a person's 'identity is all about the spiritual journey'. Hence, identity and spirituality go hand in hand. Identity formation is the development of a person's unique sense of self that is distinct from other people. Identity develops from 'the dialectic between individual and society' (Berger \& Luckmann 1976:195). The construction of an individual's reality, in dialectic with the world or society, is how the individual forms identity as he or she finds his or her place within the world. People do not just 'take over' society from 'autonomous creations', but they 'take over' the world from people who live in the world (Berger 1969:150). Children learn from their parents, engaging with their parent's world to form identity. Children begin to shape, form and then later challenge this world, as their linguistic skills improve. Hay and Nye (1998:4) explain that children's transcendent experiences are not 'culturally constructed illusions, but have an objective reality'. Hence, children's spirituality is not only formed by cultural illusions, but is grounded in 
experiences that help in the search for meaning and may even help transcend and transform their ego (see Finnegan 2008; Harris 2007). In a world where multiple discourses take place at the same time, all the time, especially through social media, the adolescent in his or her journey into adulthood may be inundated with what he or she is assimilating from his or her social environment.

\section{The adolescent's morals and values}

If adolescents are from families that follow organised religions, they would not only know what has been taught by their parents and grandparents but also by spiritual leaders (Doka 2011). Up until now, these morals and values have been part of their spiritual identities. What they may be exploring within their youth or popular culture, such as sex, pornography and drug experimentation, goes against these values. The resulting feelings of guilt and loneliness are described by Coles (1998) as follows:

It's a loneliness that has to do with a self-imposed judgment of sorts: I am pushed and pulled by an array of urges, yearnings, worries, fears, that I can't share with anyone, really - and don't wish to, even as I wonder about another's, their thoughts, their emotions. (p. 143)

The lonely adolescent is under the impression that no one wants to make an effort to understand him or her and the anxiety that he or she is experiencing. Adolescents can be harsh judges of not only themselves but also their friends, parents and the social context (Fowler 1981:71).

\section{The adolescent and choices}

The adolescent has choices to make and these choices concern who the adolescent wants to be and the values that they want to embrace, which may come at a cost. While the adolescent may not want to disappoint his or her parents, he or she would also want to fit in with his or her friends and the youth or popular culture that they so eagerly embrace. Finding a balance between the two may prove difficult for the adolescent. Adolescents have to learn that the choices they make affect them and also those around them. Adolescents are part of a larger community and on some level, their actions, whether on a small or large scale, have consequences within that community. This ability to choose plays a fundamental role in the purpose and participation of peoples' search for answers to the ultimate questions. Hence, the choices people make may:

shape their life in a meaningful way. A civilised culture needs individuals who have developed ways of expressing and communicating their emotions, who are sensitive to the transrational, who have a language for their deepest longings and anxieties and for the encounters with the beautiful and the uncanny. (Heimbrock 2010:129)

\section{Doka (2011) explains how:}

... it is critical for the adults around the adolescent to understand and respect that struggle wherever direction that may lead. Some may reject the beliefs they were carefully taught - defining their own explanations, their individual spirituality - however expressed. Some, after a period of exploration, may return to the family's faith. Others may not.

Raftopoulos and Bates (2011:164) suggest that counsellors be more 'sensitive to adolescent's inner life and create a nonjudgmental environment where this could be explored'.

\section{The adolescent in Fowler's stages of faith}

Fowler's (1981) Stages of Faith sought to develop the idea of a developmental process of human faith. There are six stages: (1) Intuitive-projective faith (2-7 years of age); (2) Mythicliteral faith (7-12 years of age); (3) Synthetic-conventional faith (12 + years of age); (4) Individuative-reflective faith (21+ years of age); (5) Conjunctive faith (35 + years of age); (6) and Universalising faith $(45+$ years of age). Stage three is the adolescent stage, 'but for many adults it becomes a permanent place of equilibrium' (Fowler 1981:172). It can be a conformist stage, as what other people think about the adolescent is vital to the adolescent; some people never outgrow this stage (Fowler 1981:172), hence the reason why adolescents feel the need to fit in and explore youth or popular culture. This is the stage where the human being may first use operational thinking allowing for the person to 'reflect upon one's thinking' (Fowler 1981:152). Now is the time for the adolescent to assess the meaning of his or her life. When the adolescent is ready to move to stage four, ${ }^{2}$ he or she may have conflicting thoughts and 'serious clashes' with what he or she previously valued. These 'tensions' are pivotal in the adolescent's life to help him or her to seriously take on responsibility of his or her 'own commitments, lifestyle, beliefs and attitudes' (Fowler 1981:182). These tensions include 'serious clashes or contradictions between valued authority sources' (Fowler 1981:173). As was explained above, these clashes and contradictions may eventually help the adolescent to choose who they want to be and the values they choose to live by.

\section{Spirituality}

Apart from experiencing all this emotional upheaval, the adolescent now starts developing the ability to think critically (Doka 2011; Piaget 1972:12). With critical thinking comes the spiritual questions of Who? Why? and What? in a more intense way. These are the ultimate questions that help people on their spiritual journey. These ultimate questions are not only asked by adolescents but also children and adults. Spiritual development is a lifelong quest, but it appears that the period where the adolescent is about to enter into adulthood can sometimes be a 'gateway' to a spiritual identity that 'transcends' (Templeton \& Eccles 2006:260). Good and Willoughby (2008:35) explain that 'developmental changes that occur during and following puberty, adolescence may be a sensitive period for spiritual development'. Hence, the ultimate questions may lead the adolescent to whom they will eventually choose to become.

2.Stage four: this stage approximately begins at the age of 21 and is marked by a person taking responsibility for the actions and consequences of his or her life (Fowler 1981:182). 
Spirituality, for the purpose of this article, is understood as 'certain life-enhancing beliefs about human dignity, human rights, and reverence for life' (Witmer \& Sweeney 1992:141). All human beings are spiritual (Hay \& Nye 1998:57). Spirituality is an 'innate human characteristic' (Perrin 2007:20). Spirituality is for Harris (2007:13) 'a craving deep within each human being for meaning'. However, people also seek more than the purpose and reason for their existence. Eaude (2012:17) observes that spiritual development ${ }^{3}$ 'concerns itself with what is most important about ourselves as people'. People may also be seeking to make a connection with the mystery that surrounds the sacred and a higher power, such as God (Tracey 2003:11). Spirituality is a way for the human ego to transcend and transform (Finnegan 2008:23). Faith, explains Sheldrake (2005:297), 'involves a decision to trust rather than a logic that verifies'. Fowler (1981:15) describes faith as follows: 'Faith has to do with the making, maintenance, and transformation of human beings'. Fowler (1981:15) explains that faith is expressed through 'symbols, rituals, and beliefs of particular religious traditions'. However Fowler (1981:16) points out that 'faith is not always religious in a cultural or institutional sense'. In other words, people may find and make meaning of their lives from sources that do not have a particular religion at their core. Hence, faith and spirituality are less about what is seen and more about what is personally experienced (and this includes religious practices and rites).

\section{The importance of spirituality in the adolescent life}

Witmer and Sweeney (1992:140) explain that people need to have the following five 'characteristics of wellness' to have a healthy life span: spirituality, self-regulation, work, love and friendship. These five characteristics are part of a 'wheel of wholeness'. 'At the centre of wholeness is spirituality' (Witmer \& Sweeney 1992:140). Spirituality helps people cope with everyday stresses by giving them hope and meaning in life through the values they live out on a daily basis (Witmer \& Sweeney 1992:141). Hence, spirituality is a vital part of a human being's everyday life experience. According to a study conducted by Raftopoulos and Bates (2011:163), spirituality is an 'important aspect of adolescence' in adolescent resilience. It appears that spirituality helps adolescents recover from the low points experienced in their lives. 'Spirituality fostered perspective by providing a sense of protection, security and comfort' in the adolescents who were questioned in the study (Raftopoulos \& Bates 2011:163). Adolescents primarily search for spirituality from religions (those of their parents or may explore alternative religions) and youth or popular culture (the books they read, the music they listen to, the movies they see and so on). There are adolescents who refer to a personal relationship with God (Raftopoulos \& Bates 2011:157), while other adolescents have 'New Age ideas of the spirit' (McAvan 2012:8) referring to angels, demons, aliens and other

3.Child and adolescent spiritual development is a huge topic that has been researched from many different perspectives. Psychologists, psychiatrists, educators and from many differs theologians, in other words many of those professionals who come into direct contact with children, write about what they have observed or undertake studies on children and their spiritual experiences. The following works offer a handful of examples: Coles (1998); Eaude (2006); Harris (2007, 2014); Hay and Nye (2008); Hyde (2008); Ratcliff (2004); Roehlkepartain et al. (2006); Tracey (2010); Yust et al. (2006) supernatural beings. Clark (2002:795) calls this supernatural tendency by adolescents to search for spirituality as the 'funky' side of religion.

Kessler (1998:49) explains that in extreme situations, adolescents may turn to 'drugs, gang violence, and even suicide' as 'a search for connection and meaning and an escape from the pain of not having a genuine source of spiritual fulfilment'. There are also adolescents who suffer from a mental-health problem, such as aggression, depression and anxiety, as a result of the high divorce rates, adolescent pregnancy and unstable environments, who find spirituality to be a coping mechanism to counter these issues (Bruce \& Cockreham 2004:334; Raftopoulos \& Bates 2011:151).

\section{The lived experiences of adolescent spirituality through popular culture}

This article will build on a lived theology perspective of how the sacred can be experienced in the sources offered by popular or youth culture that may become sacred spaces where the adolescent can experience and express their spiritual search. Lived theology pays attention to how people utilise, practice and express the sacred in everyday life within a particular social context to experience transformation and transcendence (see Ganzevoort 2009; Gräb 2012; Heimbrock 2010; Miller-McLemore 2012).

\section{Popular culture or youth culture}

As was said above, when adolescents do not have a genuine source of spirituality that they can explore and seek answers to the ultimate questions, adolescents may explore 'false spiritual sources' to help escape what they perceive as their meaningless existence (Kessler 1998:49). 'False spiritual sources' are sources that people may use in search of escape, rather than growth, and may cause chaos rather than transcendence. Spiritual sources can be sought and found in a variety of places. Popular culture is one possible spiritual source, and the most likely source to which adolescents will turn to (see Apostolides 2016; Apostolides \& Meylahn 2014; Clark 2002:794-811). When adolescents start challenging their parents' values, they often become involved in popular or youth culture, the social culture created by young people as a means of self-expression. Lynch (2005:3) explains how popular culture relates to 'other cultures' as follows: (1) opposes high culture or the avant-garde; (2) is seen to displace folk culture; and (3) is a form of social and cultural opposition against dominant or mass culture. Hence, popular culture is a culture created by young people to oppose what adults are conforming to. Arnett (1995:525) points out that there are also youth subcultures 'to carve out a subculture identity that is distinct not only from larger society but from other youth subcultures, as well'. Adolescents often look to popular culture (their social context) to search for meaning in their lives, and use these values and meanings that they assimilate to express their spiritual selves and identities. Adolescents may use popular culture as alternative spiritual sources, to their parents, to understand their place within their own youth social-cultural space. 'Popular culture directly 
enables religious participation, transformation, understanding and experience' (Partridge 2004:141). Hence, this type of participation and interaction with popular or youth culture can be called a lived theology. McAvan (2012:5-10) has coined the phrase 'postmodern sacred' to explain popular cultural spirituality that has been sacralised and is used by adolescents to explore and shape their spirituality (McAvan 2012:7). As these genres often deconstruct chaotic contemporary discourses and then reconstruct alternative discourses that offer alternative solutions, the adolescent reader or movie goer may use these alternative discourses to explore and shape their spiritualties according to the alternative discourses.

\section{The adolescent and media}

Within popular culture or youth culture, adolescents use media to form identity, spirituality and express and cope with emotion, and this helps adolescents connect to peer networks (Arnett 1995:521-524). From her research with American adolescents, Clark (2002:808) identified five different ways in which adolescents either 'affirm or blur the supposed boundaries between the beliefs about the realm beyond from religion and similar beliefs popularised by media'. These 'ways' are listed as follows:

1. Traditionalist: Affirming the boundaries between religion and media. These adolescents were often part of conservative religion and strictly separated their religion from supernatural stories presented in the media (stories that include witches, wizards, vampires, ghosts, aliens and supernatural events) (Clark 2002:799).

2. The intrigued teens: Wishing to separate religion and legend. These adolescents had similar ideas to the first group, but sometimes blurred their religion with the supernatural stories that presented aspects of their religions by the media (Clark 2002:801).

3. The mystical teens: Religion informs teen culture experience. These adolescents interlaced their religious beliefs with the supernatural stories presented in the media with a mystical understanding (Clark 2002:802).

4. The experimenters: Appreciating both legitimate and delegitimated religion. These adolescents eagerly pursued resources from the media (Clark 2002:808).

5. The resisters: Loving the supernatural and hating organised religion. These adolescents don't believe in and challenge organised religion, but believe in the supernatural presented by the media (Clark 2002:808).

Clark (2002:808-809) made three findings from the above research: (1) it established that 'religious identity and religious belief may not be directly related' to the adolescents' association or lack of association with a religion; (2) adolescents may identify with the supernatural realm as they feel powerless to their social context. Clark (2002:809) points out that this powerlessness may change towards their social context as they mature, but adolescents' views to religious identity may remain shaped by their early views on the supernatural; and (3) this research established 'that media, as an element of culture, echo contradictory approaches to religion within the culture' (Clark 2002:809).
The above research is a good example of how adolescents use their social context and particularly popular culture to form a spiritual identity and search for meaning. Most of the adolescents in the study regardless of their religious practices, or lack thereof, were at the very least curious, while others openly searched alternative spiritual sources in their search of the mysterious or supernatural realm. Therefore, by knowing, understanding and discussing with the adolescent as to why the above sources are so appealing to them, the adult may better guide the adolescent.

\section{The adolescent and the problems presented by social media}

Arnett (1995:530) warns that the choice of media made by the adolescent may cause her and/or him to become confused. In this context, media refers to communication such as music, magazines, clothing trends and so on. This type of media may promote different values to what his or her parents find appropriate. Social media in this context refer to the internet and the tools that are used to network using the internet. Not all media and social media are bad or dangerous. Media and social media, when used responsibly, are tools that allow the user access to a wealth of information. However, adult concerns regarding social media are sometimes well-founded, as social media (such as Facebook, Instant Messaging, Twitter and so on) (South African Government 2015) are not only inappropriate for youth but may also be damaging to their spiritual identities. The damage done to adolescents from sexting alone is inconceivable (South African Government 2015). Perrin (2007:24) speaks of authentic and inauthentic spirituality and cautions that some spiritualties may cause irreversible harm: 'Human spirit is not absolutely benevolent. Without careful attention, it can be led astray, resulting in destructive and harmful human actions' (Perrin 2007:24). Authentic spirituality is a life-enhancing expression of 'self-liberating transcendence ... directed toward the common good of humanity', whereas 'clusters of values, actions and choice, such as alcoholism, Nazism, or consumerism ... have mistaken the quest of the human spirit and cannot be considered authentic expressions of spirituality'. If identity is an essential part of spirituality, and if the choices made by individuals have an impact on their identity and spirituality, then the choice to take drugs, drink alcohol, partake in inappropriate sexual activities and follow radical groups to name but a few such actions and choices are mistaken quests, and therefore, inauthentic spiritualties. These types of spiritualties are the antithesis of what spirituality actually is, as the values, actions and choices made by the adolescent lead to the degrading, not only of the individual but also of his or hers actions towards their everyday lived experiences. There is nothing sacred experienced in these actions or spaces, and can then be termed 'corrupted spiritualties'. 'Corrupted spiritualties' may be contributing to the breakdown of communities rather than adolescents positively contributing to their societies. 


\section{The adolescent and adult support and guidance}

Doka (2011) and Raftopoulos and Bates (2011:164) have explained how crucial it is for adults to make an effort to understand and respect the struggle that the adolescent is experiencing. As being misunderstood is part of the adolescent's journey (Coles 1998:134), it is perhaps of vital importance to show some acceptance to the adolescent of their views. Bruce and Cockreham (2004:341) explain that if adolescents are encouraged and are helped to make spiritual connections with an adult they respect, adolescents may live out healthy spiritual lives, helping the adolescent overcome and counteract cultural problems. Adults need to allow and perhaps even encourage adolescents to use aspects of popular or youth culture in a positive way. The adolescent may use aspects of this culture that they hold so dear to cope with this stage of their lives, instead of constantly feeling misunderstood. Perhaps, counsellors, parents and teachers could create nonjudgemental environments at home and in the classroom to guide adolescents and help them explore their social environment in a safe way, instead of dismissing youth culture as a phase the adolescent is going through. Bruce and Cockerham (2004:341), researching on adolescent girls, explain that: 'adolescent girls who choose and seek access to a nonparent adult are choosing to augment and strengthen their voices and personal development'. It appears that the correct adult approach and approval are crucial to the adolescent even though they may be saying something different.

The adult, and this may include a favourite parent, uncle or aunt, may read a favourite book, watch a movie or listen to a beloved band that the youth is so 'into'. By making the effort to partake in such an activity, the adult may create an opportunity to open a conversation with the adolescent, to share why the adolescent identifies so much with that particular aspect of 'youth culture'. As was said above (Raftopoulos \& Bates 2011:163), spirituality helps adolescents be resilient to the ups and downs of life. By listening to adolescents' stories, the adult may help them make sense of their stories and their place within their stories. Fantasy books and movies (see Apostolides 2016; Clark 2002) are forms of popular culture that allow for sacred transformation to occur. Music is also explored by adolescents as they sometimes use 'meaningful songs' or create their own music and then share these experiences with others (Raftopoulos \& Bates 2011:164).

\section{Conclusion}

Being an adolescent is a difficult time for young people. Adolescents are awkward, and insecure, and do not want to be left out of what their peers are doing. The adolescent may feel isolated from his or her family if he or she is doing things that he or she knows his or her family would disapprove of. However, if the adolescent is complying with what is expected of him or her at home, he or she may feel isolated from his or her peers. At this stage of their lives, adolescents struggle to make a connection with what they have, up until now taken for granted as their spiritual identity, and try to carve out a spiritual identity that is unique to them. Hence, adolescents may make choices at this stage that may inadvertently shape the rest of their lives.

Research shows that adolescents look to their youth culture to explore, understand and experience their spiritual selves, shaping their identity. By being allowed to explore and live out spiritualties in their own way within their own youth culture, supported by the adults in their lives, may allow for a happy adolescent. Adults can act as guides to adolescents to make spiritual connections within the adolescents' own social contexts. In this way, the adolescent may move into adulthood as a person that will take on the responsibility of being an adult not only within/his or her personal life but also a responsible member of the community.

However, popular or youth culture is multi-layered with many aspects to be taken into consideration. Adolescents are bombarded by social media within their social context or youth culture. While some aspects of popular or youth culture offer healthy spaces for spiritual exploration, others, like some forms of social media, can cause unimaginable damage. There are spiritualties that are damaging to the adolescent, and guidance from an adult may prove to be of great value to the adolescent.

\section{Acknowledgements Competing interests}

The author declares that he has no financial or personal relationships which may have inappropriately influenced him in writing this article.

\section{References}

Apostolides, A., 2016, 'South African fantasy: Identity and spirituality', HTS, Teologiese Studies/Theological Studies 72(1), 1-5. https://doi.org/10.4102/hts.v72i1.3255

Apostolides, A. \& Meylahn, J.-A., 2014, 'The lived theology of the Harry Potter series', HTS, Teologiese Studies/Theological Studies 70(1), 1-6. https://doi.org/10.4102/ hts.v70i1.2713

Arnett, J.J., 1995, 'Adolescents' uses of media for self-socialization', Journal of Youth and Adolescence 24(5), 519-533. https://doi.org/10.1007/BF01537054

Berger, P.L., 1969, The sacred canopy: Elements of a sociological theory of religion, Anchor Books, New York.

Berger, P.L. \& Luckman, T., 1976, The social construction of reality: A treatise in the sociology of knowledge, Penguin Books, London.

Bruce, M.J. \& Cockreham, D., 2004, 'Enhancing the spiritual development of adolescent girls', Professional School Counseling 7(5), 334-342.

Clark, L.S., 2002, 'U.S adolescents religious identity, the media, and the "funky" side of religion', Journal of Communication December, 794-811. https://doi.org/10.1111/ j.1460-2466.2002.tb02574.x

Coles, R., 1998, The moral intelligence of children: How to raise a moral child, Plume, New York.

Doka, K.J., 2011, 'Adolescence, identity and spirituality', The Huffington Post, viewed n.d., from http://www.huffingtonpost.com/kenneth-j-doka/adolescence-identityand-_b_858804.html

Eaude, T., 2012, 'Spiritual and moral development', in L.P. Barnes (ed.), Debates in religious education, pp. 120-131, Routledge Taylor \& Francis Group, Oxford, UK.

Finnegan, J., 2008, The audacity of spirit. The meaning and shaping of spirituality today, Veritas, Dublin.

Fowler, J.W., 1981, Stages of faith, Harper \& Row, San Francisco, CA.

Ganzevoort, R., 2009, 'Forks in the road when tracing the sacred: Practical theology as hermeneutics of lived religion', in Presidential Address to the Ninth Conference of the IAPT in Chicago, viewed 20 May 2013, from www.ruardganzevoort.nl

Good, M. \& Willoughby, T., 2008, 'Adolescence as a sensitive period for spiritual development', Child Development Perspectives 2(1), 32-37. https://doi.org/ 10.1111/j.1750-8606.2008.00038.x 
Gräb, W., 2012, 'Practical theology as a religious and cultural hermeneutics of Christian practice', International Journal of Practical Theology 16(1), 79-92. https://doi.org/10.1515/ijpt-2012-0007

Harris, K.I., 2007, 'Re-conceptualizing spirituality in the light of educating young children', International Journal of Children's Spirituality 12(3), 263-275. https:// doi.org/10.1080/13644360701714936

Harris, K.I., 2014, 'Embracing make believe and play and theories of childhood: Understanding children's spirituality and the spiritual essence of a young child', International Journal of Integrative Pediatrics and Environmental Medicine $12-21$.

Hay, D. \& Nye, R., 1998, The spirit of the child, Harper Collins, London.

Heimbrock, H.G., 2010, 'Beyond secularization: Experiences of the sacred in childhood and adolescence as a challenge for RE development theory', British Journal of Education, viewed 27 November 2013, from http:/www.tandonline. com/loi/cbre20

Hyde, B., 2008, 'The identification of four characteristics of children's spirituality in Australian Catholic primary schools', International Journal of Children's Spirituality 13(2), 117-127. https://doi.org/10.1080/13644360801965925

Kessler, R., 1998, 'Nourishing students in secular schools', Educational Leadership 56(4), 49-52.

Lynch, G., 2005, Understanding theology and popular culture, Blackwell Publishing, Oxford.

McAvan, E., 2012, The postmodern sacred: Popular culture spirituality in the science fiction, fantasy and urban genres, McFarland \& Company Inc. Publishers, London.

Miller-McLemore, B.J., 2012, 'Theology, religious communities and practice', viewed 12 June 2016, from http://www.faithandleadership.com/qa/bonnie-j-miller-mclemore

Sheldrake, P., 2013 [2005], The new SCM dictionary of Christian spirituality, SCM Press, London.

Partridge, C., 2004, The re-enchantment of the West, vol. 1, T \& T Clark International, London.

Perrin, D., 2007, Studying Christian spirituality, Routledge, London.
Piaget, J., 1972, 'Intellectual evolution from adolescence to adulthood', Human Development 15(1), 1-12. https://doi.org/10.1159/000271225

Ratcliff, D. (ed.), 2004, Children's spirituality: Christian perspectives, research and applications, Cascade Books, Eugene, OR.

Raftopoulos, M. \& Bates, G., 2011, “It's knowing that you are not alone": The role of spirituality in adolescent resilience', International Journal of Children's Spirituality 16(2), 151-167. https://doi.org/10.1080/1364436X.2011.580729

Roehlkepartain, E.C., Ebstyne King, P., Wagner, L. \& Benson, P.L. (eds.), 2006, The handbook of spiritual development in childhood and adolescence, Sage, Riverside, CA.

Sax, L., 2010, Girls on the edge, Basic Books, New York.

South African Government, 2015, Basic education on the dangers of social media for adolescents, viewed 20 August 2016, from http://www.gov.za/speeches/sextingspare-rod-teach-child-18-may-2015-0000

Templeton, J.L. \& Eccles, J.S., 2006, 'The relation between spiritual development and identity processes', in E.C. Roehlkepartain, P. Ebstyne King, L. Wagner \& P.L. Benson (eds.), The handbook of spiritual development in childhood and adolescence, pp. 252-265, Sage, Riverside, CA.

Tacey, D., 2003, 'Rising waters of the spirit', Studies in Spirituality 13, 11-30, viewed 20 May 2016, from https://doi.org/10.2143/SIS.13.0.504586

Tracey, D., 2010, 'What spirituality means to young adults', in S. Collins-Mayo \& P. Dandelion (eds.), Religion and youth, pp. 65-72, Ashgate Publishing Company, Burlington.

Witmer, J.M. \& Sweeney, T.J., 1992, 'A holistic model for wellness and prevention over a life Span', Journal of Counseling \& Development 71, 140-148. https://doi. org/10.1002/j.1556-6676.1992.tb02189.x

Yust, K.M., Johnson, A.N., Sasso, S.E. \& Roehlkepartain, E.C., 2006, 'Traditional wisdom: Creating space for religious reflection on child and adolescent spirituality', in K. Yust, A.N. Johnson, S.E. Sasso \& E.C. Roehlkepartain (eds.), Nurturing child and adolescent spirituality: Perspectives from the world's religious straditions, pp. 253-263, Rowman \& Littlefield Publishing Group, Inc., Mitchellville, MD. 